\title{
How to Manage and Generate Positive Attitudes and Behaviors in Physicians
}

\author{
Araújo CAS*, Figueiredo KF \\ COPPEAD -Federal University of Rio de Janeiro.
}

*Corresponding Author: E-mail: claraujo@coppead.ufrj.br

\begin{abstract}
This article aims to identify the best possible working environment hospital managers should offer physicians in order to generate job satisfaction, organizational commitment and organizational citizenship behavior among these professionals, improving the quality of services delivered to patients. A survey was applied to 174 physicians from five private hospitals in Brazil. Both factor analysis and regression analysis were used to analyze the study's model. The findings indicate that in order to stimulate positive behaviors and attitudes in physicians, managers should promote a good working environment amongst the staff, and create an environment free of discrimination on grounds of age, gender and race. Hospital leaders should encourage trusting relationships with doctors through clear, effective and respectful communications. It's also important to offer development opportunity for these professionals and a good work infrastructure.
\end{abstract}

Keywords: Brazil, Job satisfaction, Internal climate, Organizational commitment, Organizational citizenship behavior, Physicians, Private hospitals, Working environment.

\section{Introduction}

The primary objective of this article is to investigate how to manage physicians in order to generate positive behaviors and attitudes in relation to the hospital in which they work. Basically, the purpose of this article is to identify the kind of working environment that should be offered by hospital leaders to their physicians to generate job satisfaction, organizational commitment and organizational citizenship behavior within their field of expertise. To achieve this objective, a survey was supplied to 636 physicians working within five private hospitals in Brazil.

Physicians perform a dual function in hospital institutions: they act as clients of services offered by the hospital, depending on its resources to appropriately carry out their job, and at the same time, as providers of medical services to the hospital's patients [1]. The activity carried out by these professionals contains a high degree of autonomy. They tolerate little or no influence on the way they do their work, making the coordination of their actions within the hospital complex. This picture provides evidence of the challenges faced by hospital managers to adequately manage the clinical staff and the importance of creating a good working environment for the physicians so as to provide efficient services to the patients.
This study is important and relevant because it focuses on a complex sector that over the last few years has been receiving increased attention from academics. While most articles investigate nurses, this research focuses on physicians, who have received little attention in previous studies. Moreover, hospital leaders face huge managerial challenges regarding physicians and this study intends to help them to advance these professionals.

\section{Literature Review}

Hospitals are institutions characterized by the fact that decision-making powers, administration and distribution of resources are divided up amongst an important group of professionals -the physicians, nurses and nutritionists for example. Mintzberg [2] classifies these institutions as professional bureaucracies in which power is concentrated with highly specialized professionals -the physicians - who are actually performing the work. Also, it's essential to take into account that physicians perform two different functions in hospitals: acting as clients of the services offered by the hospital, depending on the institution and its resources to perform its work properly and at the same time, acting as an employee, providing medical services to the patients [1]. 
In this sense, [3] argues that physicians have been regarded as elite professionals desirous of autonomy and as rational suppliers of services to patients. However, medicine is a job as much as a profession and is therefore subject to fears, rewards, challenges, opportunities, disappointments, frustrations, uncertainties and hopes. Seeing physicians as workers draws them closer to their peers - nurses, technicians and other professionals-who also struggle to give meaning to their jobs. As workers, physicians engage not only in short-term changes but also in relationships based on social interaction and identification [3]. The results of the research conducted by Ozaki et al. [4] with 82 doctors from hospitals in Japan are aligned with Hoff's understanding, where the researchers pointed out the relationship with other doctors and staff as dimensions of doctors' satisfaction on the job.

The literature, however, has portrayed physicians as highly trained, autonomous professionals and as key furnishers of the health "product", and whose attitudes have a purely rational motivation. From this perspective, the physician retains exclusive control in defining working terms and conditions. This perspective portrays physicians as highly rational beings, who want to be "left in peace" while working. On the other hand, physicians can be seen as employees who want to create a psychological contract with their employers, based on relationship and mutual trust [3-4].

\section{The Concept of Internal Climate for Physicians}

There are various labels found in the literature regarding concern about the human element in organizations: quality of internal services, quality of life at work, endomarketing, internal marketing, service climate, internal climate, etc. Each one of these constructs has arisen within the most diverse areas of knowledge such as service management, marketing, human resources, organizational behavior and social sciences, such as psychology and sociology. In the present study, the construct named internal climate for physicians can be defined as the work environment offered by the organization to these professionals, in order to generate positive consequences, such as greater job satisfaction, organizational commitment and organizational citizenship behavior [5-7].

According to the literature, internal climate for physicians is a multidimensional construct and in order to identify its dimensions a broad bibliographical review concerning the health sector was carried out. Due to space limitations, the dimensions of internal climate for physicians that emerged from the literature, its attributes, and authors who have proposed them are summarized in Table 1.

\section{The Positive Consequences of Internal Climate for Physicians}

The direct consequences of internal climate that arise from the literature and that have been taken into consideration in this study are as follows: job satisfaction (JS), affective commitment (AC) and organizational citizenship behavior (OCB). In turn, these positive consequences improve the quality of services delivered to patients and increase the productivity of professionals who, motivated for and committed to the institution, perform a more accurate examination of patients, thereby improving diagnoses as well as reducing the number of medical errors [12, 19, 20].

Job satisfaction may be defined as an employee's positive emotional state in relation to the job, which derives from aspects related to the characteristics of the work itself, such as working conditions and workload, and the intrinsic characteristics of the person, such as personality, education, age and gender [9,15,18, $19,21,22$,$] . Apart from the aspects related to the$ individual's personality, highlighted by Matzler and Renzl [19], academics have found in their research that there is a positive relationship between job satisfaction and trust in leaders; effective internal communication and role clarity [9]. In their research with 428 physicians working in the emergency room of Canadian hospitals, Williams et al. [11] concluded that a strong culture of doctor's development is one of the antecedents of job satisfaction. Rad and Yarmohammadian [23], in turn, conducted a study with 814 employees of 12 university hospitals located in Iran and found that the style of leadership is strongly related to job satisfaction. According to Williams and Skinner [23], the decline of job satisfaction among physicians may negatively impact the quality of patient care.

Organizational commitment, in turn, may be defined as a psychological, emotional link between employee and company $[22,24,25]$. Allen and Meyer [26-27] have proposed an organizational commitment model composed of three elements: the affective component - emotional bond, identification and involvement with the organization; the employee stays with the company "because he or she wants to"; the 
continuity component - commitment based on costs associated with leaving the company; in this case, the employee stays with the organization "because he or she has to"; and the normative component - employees remain with the company "because they feel obligated to." Having the characteristics of hospitals in mind, these institutions must promote factors that encourage affective commitment. Plus, organizational commitment is especially important for health organizations, since their professionals struggle to maintain a high quality of treatment for the patient within an environment of scanty

Table 1: Dimensions of internal climate for physicians

\begin{tabular}{|c|c|}
\hline Dimension & Attributes \\
\hline & Good relationship with the hospital's \\
\hline & leaders. Clarity about the hospital's mission \\
\hline & and objectives. Effective internal \\
\hline & communication. Avoidance of excessive \\
\hline & work hours and inflexible schedules. \\
\hline Trust & $\begin{array}{l}\text { Avoidance of excessive physical and mental } \\
\text { workload. The observance of work safety. }\end{array}$ \\
\hline & Equal division of duties, hierarchy of \\
\hline & $\begin{array}{l}\text { command and control. Participation in the } \\
\text { institution's decisions. Respect for the }\end{array}$ \\
\hline & $\begin{array}{l}\text { clinical staff. Maintenance of the } \\
\text { psvchological contract. }\end{array}$ \\
\hline Justice & $\begin{array}{l}\text { Fairness and impartiality perceived in the } \\
\text { leader's actions. }\end{array}$ \\
\hline Pride & $\begin{array}{l}\text { Pride regarding the profession, the institution } \\
\text { and the characteristics of the work per se. }\end{array}$ \\
\hline Camaraderie & $\begin{array}{l}\text { Friendly environment. Good interaction with } \\
\text { other professionals, forming a team. Absence of } \\
\text { physical and verbal aggression among team } \\
\text { members. }\end{array}$ \\
\hline Work Infrastructure & $\begin{array}{l}\text { Adequate resources for taking care of patients } \\
\text { (physical structure, medicines, instruments and } \\
\text { adequate equipment). Planning and } \\
\text { organization of the workspace - work } \\
\text { instruments are always in the right place and } \\
\text { are easy to find. Adequate contingent of } \\
\text { professionals. }\end{array}$ \\
\hline
\end{tabular}

Training

and development

Reward recognition

and Recognition of effort put forth. Possibility of promotion and professional growth. Feedback from superiors. Career planning. Prospects for promotion. Recognition by patients.

Adequate pay for responsibility of services performed. Monetary benefits. Bonuses and nonmonetary benefits. Adequate economic reward.
Authors

Peduzzi [8]; Mano-Negrin, [9]; Rad and Yarmohammadian [10]; Williams et al. [11]; Henry and Julius[12]; Miryala and Thangella [13].

Lyman, [14]; Rego and Souto [7]; Lambrou et al. [15].

Lambrou, et al., [15]; Miryala and Thangella [13].

Lambrou et al., [15]; Iliopoulos and Priporas [8]; Kartal, et al., [16]; Miryala and Thangella [13].

Lambrou et al. [15]; Kairys, Zebiene, Sapoka, and Zokas [17]; Miryala and Thangella [13].

Mano-Negrin, [9];

Iliopoulos and Priporas [18].

Mano-Negrin [9]; Lambrou, et al., [15]; Iliopoulos and Priporas [18].

Mano-Negrin [9]; Lambrou, et al., [15]; Iliopoulos and Priporas [18]. resources. The concept organizational citizenship behavior (OCB) is characterized by spontaneous and unconditional behaviors engaged by individual personnel beyond the organization's officially requested responsibility. This behavior is beneficial to the organizational system and can foster its efficiency, but not directly recognized by the formal reward system [20,28]. It entails activities of cooperation with colleagues, protective actions of the institution, creative suggestions for organizational improvement, self- training for a better work performance, and the creation of a favorable climate for the organization [26]. Therefore, the concept of organizational citizenship behavior ensures that employees are willing to contribute to the hospital as much as possible by enhancing their sense of belonging to the health care organization [29].

\section{Proposed Conceptual Model and Research Hypothesis}


The literature indicates that a good internal climate can generate positive attitudes and behaviors on physicians. Therefore, the analytical model proposed in this study relates to a series of internal climate dimensions for physicians' positive behaviors and attitudes (Fig.1), and the following general hypothesis has been formulated: H1-physicians' positive attitudes and behaviors may be explained by the dimensions of internal climate for these professionals. The dimension related to pay and benefits was not included in the model because not all physicians have a formal employment connection with the hospital where they work and it would hinder the analysis of the results.

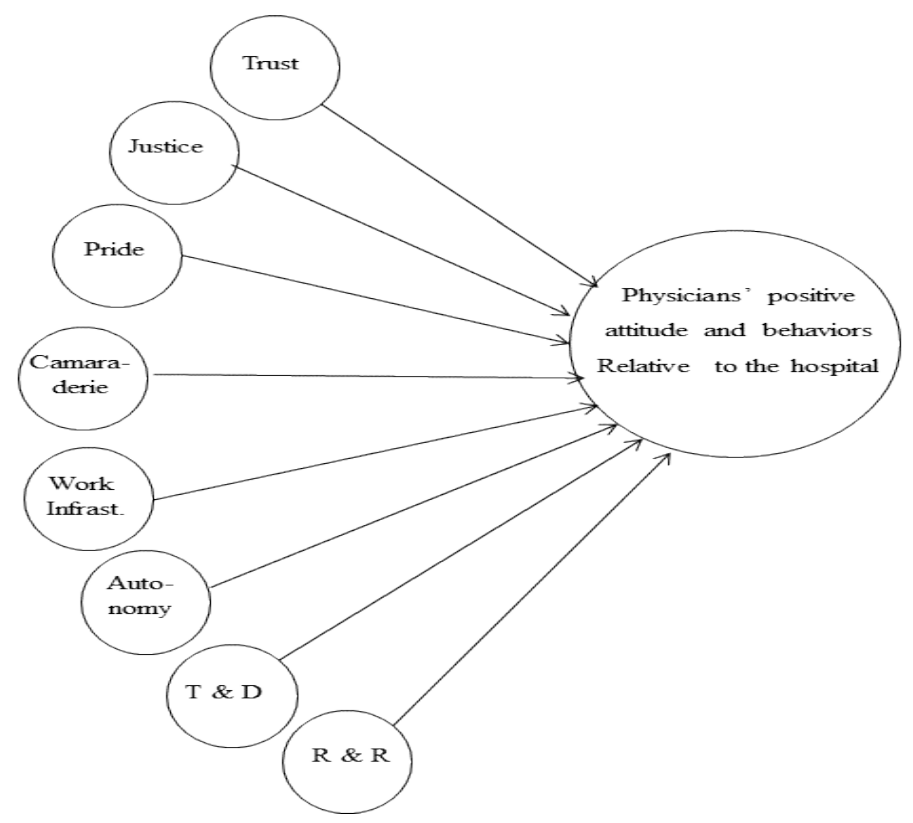

Fig. 1: Proposed conceptual model

\section{Methodology}

Based on the literature, a standardized questionnaire of 41 items related to internal climate and 12 to its consequences was supplied to 636 physicians who work at five private hospitals in Brazil, recognized for service excellence, regardless of the labor relationship with the institution. From these, 174 physicians $(27.36 \%)$ agreed to participate in the research.

There was an adaptation to the needs of each hospital regarding the best time to apply the questionnaire and the professionals available for filling it out. After the field work, the data was entered and personally checked by the researcher. Questionnaires were regarded as valid if they were filled out by professionals who had been working at the hospital for at least one month, resulting in 168 valid questionnaires. The questionnaires were adjusted and pre-tested before applying the final version on a large scale.
The internal consistency of the scale was verified using Cronbach's Alpha - the computed values for the items of internal quality and for the items of positive consequences were 0.946 and 0.878 , respectively.

The multivariate techniques Factor Analysis and Multiple Linear Regression were applied to analyze the data (run through SPSS 19.0). The Factor Analysis was applied to the set of attributes of the internal climate and of the positive consequences in terms of attitudes and behaviors for physicians. In order to verify the adequacy of this technique, the Bartlett's test of sphericity and an examination of the KaiserMeyer Olkin measure of sampling adequacy were done. The Principal Components Analysis procedure was utilized for extracting the factors. The latent root criterion (eigenvalue $>1$ ) was adopted to select the factors. A Varimax orthogonal rotation was applied to the original factor matrix, to facilitate the interpretation of the factors. The Multiple Linear Regression was applied to verify which dimensions of internal climate (independent variables) better explained physicians' positive attitudes and behaviors. In order to perform this analysis, after applying the Factor Analysis, the following steps were followed.

\section{Determination of the PC Index}

Considering the importance of the physicians' positive attitudes and behaviors for the hospitals and, moreover, that the objective of this study was to investigate the dimensions that better explain positive behaviors and attitudes on the part of these professionals, the twelve variables were analyzed as a single construct, called Positive Consequences Index (PC Index). To calculate the $P C$ Index, the percentage of variance explained by each one of the factors was utilized together with the values of the factor scores, for each one of the respondents. The $P C$ index of respondent $i$ may be represented as follows:

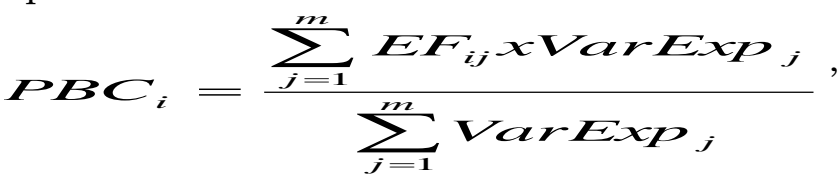

where: $E F_{i j}=$ factor score for respondent $i$ for dimension $j$; and $\operatorname{VarExp}{ }_{j}=$ variance explained by dimension $j$.

\section{Multiple Linear Regression Analysis Using the Enter Method}

Multiple linear regression analysis using the enter method to verify the contribution of each internal climate dimensions (independent variables) to predict the PC Index; and Multiple 


\section{Available online at www.managementjournal.info}

linear regression analysis using stepwise estimation to examine the contribution of each independent variable to the regression model. The beta coefficient was analyzed to verify the relative explanatory power of the dependent variables. In order to apply the multiple linear regression, an analysis of the outliers was done, using Cook's distance analysis as a criterion. To verify the constant variance, independence and normality of the error term distribution, a graphical analysis of residuals was done. Multicollinearity was avoided by the orthogonal factor rotation.

\section{Results}

\section{Demographic Profile of the Sample}

Most of the physicians who participated in the survey were male $(60,12 \%)$ aged between 31 and 50 years of age, and worked in the hospital for up to five years $(52,38 \%)$.

\section{Dimensions of Internal Climate for Physicians}

For the attributes of internal climate, the analysis yielded a seven-factor solution, which explains $68.88 \%$ of the total variance: trust; camaraderie; non-discrimination; work infrastructure; training and development; nursing contingent and autonomy. A statistically significant Bartlett's test of sphericity ( $p$ value $<0.01$ ) indicates the presence of sufficient correlations among the variables to continue with the factor analysis. In addition, the measuring of sampling adequacy (MSA) value of each variable was greater than 0.50 (most attained values greater than 0.80 ). An examination of the Kaiser-Meyer-Olkin measure of sampling adequacy suggested that the sample was factorable $(\mathrm{KMO}=0.860)$ and the observations/variable reason was 4.44 observations/variable. Commonalities were analyzed and all values were equal to or greater than 0.500. The factors were labeled based on the higher loading variables $(>0.60)$ for each factor. The dimension that groups the items related to the posture of the leaders was denominated trust, representing the trust that the physicians have in the hospital's leaders; the dimension that groups the items regarding the good relationships among colleagues was labeled camaraderie; the dimension composed of items dealing with the absence of discrimination on the grounds of age, gender or race within the work environment was called non-discrimination; the aspect covering work conditions - equipment, installations and workspace organization - was denominated work infrastructure. The dimension training and development represents the items related to the possibility of professional development, the institution's investment in the professional development of its clinical staff; nursing contingent was the label given to the dimension composed of items related to the number of nursing professionals to take care of the patients; and finally, autonomy represents the freedom conferred by the hospital to its physicians to practice medicine. The dimensions, its attributes and their loads are presented in Table 2.

\section{Dimensions of Physicians' Positive Attitudes and Behaviors}

The Factor Analysis generated a two-factor solution, which explains $63.99 \%$ of the total variance. The observations/variable reason was 14 observations for each variable investigated. The Bartlett's test of sphericity presented a $p$ value < 0.01 , indicating the presence of correlations among the variables, and the Kaiser-Meyer-Olkin (KMO) value was 0.865 , indicating the sampling adequacy. The factors were labeled based on the higher loading variables $(>0.50)$ for each factor.

The dimension denominated organizational citizenship behavior represents items that characterize the physicians' behavior as a citizen of the hospital, respecting its rules, fulfilling his or her duties adequately, and cooperating with colleagues. The dimension job satisfaction, in turn, groups items related to the satisfaction of working at the hospital, the intention of remaining at the institution and the pleasure of doing more than what the job description specifies. As previously mentioned, these two dimensions were analyzed as a single construct, called PC Index.

\section{Dimensions of Internal Climate that Best Explain Physicians' Positive Attitudes and Behaviors (PC Index)}

Table 3 shows that trust, camaraderie, nondiscrimination, work infrastructure, and training and development are dimensions statistically significant at the .000 level to explain physicians' positive attitudes and behaviors measured by the $P C$ Index. The coefficient of determination $\left(\mathrm{R}^{2}\right)$ of 0.567 indicates that $56.70 \%$ of total variation of $P C$ Index is explained by the independent variables considered in this study.

In the stepwise procedure (Table 4), at first only camaraderie is used to calculate the regression equation for predicting the PC Index; in step two, the dimension non-discrimination was added to the regression model; in the third step, trust was added, followed by training and development (fourth variable) and work infrastructure (fifth variable), resulting in an $\mathrm{R}^{2}$ of 0.586 , indicating that $58.60 \%$ of total variation of $P C$ Index is explained by these five independent variables included in the model. 
Table 4 shows that: 1 ) the $F$ ratio of 43.895 indicates that, considering the sample used for estimation, it is possible to explain 43.89 times more variation than when using the average (1\% significance level); 2) standard errors of the coefficients are low, indicating that the prediction is reliable; 3) the standardized coefficient (beta) indicates that non-discrimination and camaraderie are dimensions that most contribute to explaining the PC Index; and 4) nursing contingent and autonomy are not shown to be significant for explaining the physicians' positive attitudes and behaviors.

\section{Analysis of the Results}

Table 2: Dimensions of internal climate for physicians and its attributes.

\begin{tabular}{lc}
\hline Dimensions & Loads \\
\hline Trust & 0,791 \\
\hline Leaders facilitate my job & 0,765 \\
Leaders care about my well-being at work & 0,743 \\
Leaders are accessible & 0,740 \\
Leaders respect my individuals rights & 0,719 \\
The hospital meets my expectations & 0,642 \\
Leaders honor their promises & 0,639 \\
I know what leaders expect from my work & 0,637 \\
The work rules are clear & 0,805 \\
Camaraderie & 0,789 \\
All celebrate the success of colleagues & 0,757 \\
Colleagues help each other & 0,748 \\
Doctors and nurses are mutually supportive & 0,686 \\
Communication with colleagues is easy & 0,603 \\
We look like a big family & 0,898 \\
The working environment is friendly and sociable & 0,870 \\
Non-Discrimination & 0,856 \\
There is no discrimination by gender & \\
There is no discrimination by age & 0,772 \\
There is no discrimination by race & 0,759 \\
Work Infrastructure & 0,600 \\
The equipment is suitable for treating patients & \\
Medicines and instruments are always in the right place & 0,730 \\
The physical facilities are properly designed to treat patients & 0,718 \\
Training and Development & 0,647 \\
The hospital's nursing professionals are adequate to assist the physicians & \\
The hospital's leaders recognize my professional capability & 0,861 \\
Leaders invest in my professional development & 0,830 \\
Nursing Contingent & 0,832 \\
The number of nursing professionals is adequate to assist the physicians & 0,775 \\
The number of nursing professionals is adequate to take care of patients & \\
Autonomy & \\
I have freedom to decide on the procedures & \\
I have the autonomy to treat patients & \\
\hline
\end{tabular}

Table 3:Results of the multiple linear regression-Enter Method

\begin{tabular}{|c|c|c|c|}
\hline & $\begin{array}{l}\text { Standardized } \\
\text { Beta }\end{array}$ & t Value & Sig. \\
\hline Constant & & 1.052 & 0.294 \\
\hline Trust & 0.308 & 5.693 & $0.000 * *$ \\
\hline Camaraderie & 0.501 & 9.266 & $0.000 * *$ \\
\hline Non-discrimination & 0.514 & 9.373 & $0.000 * *$ \\
\hline Work Infrastructure & 0.229 & 4.226 & $0.000 * *$ \\
\hline Training and Development & 0.233 & 4.326 & $0.000 * *$ \\
\hline Nursing contingent & 0.042 & 0.792 & 0.430 \\
\hline Autonomy & -0.018 & -0.326 & 0.744 \\
\hline $\mathrm{R}^{2}$ & 0.567 & & \\
\hline $\mathrm{R}^{2}$ adjusted & 0.547 & & \\
\hline
\end{tabular}

\footnotetext{
* $5 \%$ significance level
}

** $1 \%$ significance level 
The Factor Analysis performed on the 41 attributes included in this study indicated the existence of seven dimensions of internal climate for physicians (trust; camaraderie; nondiscrimination; work infrastructure; training and development; nursing contingent and autonomy), but only the first five dimensions were statistically significant to explain physicians' positive attitudes and behaviors (PC Index).
A large dimension denominated trust was identified, which groups attributes related to the posture of the hospitals' leaders. It can be perceived that role clarity comprises part of this factor, represented by the variables "I know what leaders expect from my work" and "the work rules are clear." Thus, as indicated in the literature, effective internal communication, which reduces role conflict and produces role clarity, is

Table 4:Dimensions that best explain physicians' PBC index

\begin{tabular}{llllll}
\hline Model & variables entered & $\mathbf{R}$ & $\mathbf{R}^{\mathbf{2}}$ & Adjusted R & Standard error \\
\hline 1 & Camaraderie & 0.432 & 0.187 & 0.182 & 0.487 \\
2 & Non-discrimination & 0.612 & 0.374 & 0.366 & 0.429 \\
3 & Trust & 0.693 & 0.481 & 0.471 & 0.392 \\
4 & Training \& Development & 0.733 & 0.537 & 0.525 & 0.371 \\
5 & Work infrastructure & 0.766 & $\mathbf{0 . 5 8 6}$ & 0.573 & 0.352 \\
\hline
\end{tabular}

\section{Analysis of variance}

\begin{tabular}{llclll}
\hline & $\begin{array}{l}\text { Sum } \\
\text { squares }\end{array}$ & of $\boldsymbol{d} \boldsymbol{f}$ & Mean square & $\boldsymbol{F}$ & Sig. \\
\hline Regression & 27.209 & 5 & 5.44 & 43.895 & 0.000 \\
Residual & 19.216 & 155 & 0.12 & & \\
Total & $\mathbf{4 6 . 4 2 5}$ & $\mathbf{1 6 0}$ & & & \\
\hline
\end{tabular}

\begin{tabular}{|c|c|c|c|c|c|c|c|}
\hline \multirow[b]{2}{*}{ Variable } & \multirow[b]{2}{*}{ Coefficient } & \multicolumn{3}{|c|}{$\begin{array}{l}\text { Variable Entered into } \\
\text { regression model }\end{array}$} & \multicolumn{3}{|c|}{ Variables not entered } \\
\hline & & $\begin{array}{l}\text { Standard } \\
\text { error }\end{array}$ & $\begin{array}{l}\text { Standardized } \\
\text { coefficient }\end{array}$ & $t$ value & Sig & $\begin{array}{l}\text { Partial } \\
\text { correlation }\end{array}$ & $t$ value \\
\hline (Intercept) & 0.025 & 0.028 & & 0.906 & 0.366 & & \\
\hline Camaraderie & 0.275 & 0.029 & 0.492 & 9.425 & 0.000 & & \\
\hline Non-discrimination & 0.320 & 0.033 & 0.509 & 9.648 & 0.000 & & \\
\hline Trust & 0.176 & 0.029 & 0.317 & 6.061 & 0.000 & & \\
\hline Training \& Development & 0.151 & 0.030 & 0.260 & 4.989 & 0.000 & & \\
\hline Work Infrastructure & 0.124 & 0.029 & 0.224 & 4.276 & 0.000 & & \\
\hline Nursing contingent & & & & & & 0.052 & 0.645 \\
\hline Autonomy & & & & & & -0.029 & -0.365 \\
\hline
\end{tabular}

associated to the trust factor [22, 23]. Likewise, it may be perceived that the leaders' respect for their clinical staff ("the directors respect my individual rights", "the directors are concerned with my well-being at work"), the organizational support perceived ("the directors make my job easier", "the directors are accessible"), the maintenance of the psychological contract and the credibility of the leaders' actions ("the hospital meets my expectations" and "the directors honor their promises") comprise this dimension labeled trust in line with the literature reviewed [22, 23, among others].

Camaraderie also emerged as a factor of internal climate for physicians, which confirms that a good relationship between the clinical staff and other professionals is one of the dimensions by which the physicians evaluate the internal climate offered by the hospital. This result is in harmony with the understanding of Hoff [6] and with previous researches $[16,8]$.

The aspects related to the absence of discrimination on the grounds of age, gender or race were also a dimension called nondiscrimination, revealing that egalitarian treatment is one of the dimensions of internal quality for physicians. It is interesting to note that this dimension, composed only by absence of discrimination, was not found in previous researches. Within this dimension, justice comprises these attributes and others related to

fairness in procedures adopted by the company [8].

Work Infrastructure, highly emphasized in the literature [10], also formed a dimension in the present study. Therefore, the working conditions 
offered by the hospital, as well as workspace organization, compose a factor of the internal climate for physicians. However, an adequate number of nurses required to help physicians and to care for patients. Instead of composing the dimension work infrastructure as in previous studies [11], it formed another dimension named in this study - nursing contingent.

Likewise, training and development are amongst the dimensions of internal climate for physicians and represent the possibility for professional growth; it is the actual investment the hospital makes in their professional development and the recognition of their capability. These results have already been pointed out in previous studies conducted with physicians $[16,10,8]$. Finally, autonomy is a dimension related to the freedom to decide how to treat patients and to choose the most adequate procedures, confirming previous studies [10].

According to the physicians interviewed in this study, a good relationship among colleagues camaraderie - and the absence of any kind of discrimination - non-discrimination - are the dimensions of internal climate that most contribute to explain the $P C$ Index. It is interesting to note that, according to this research, these are the two dimensions that most contribute to explain physicians' positive attitudes and behaviors, because this result is in line with Hoff's reasoning [6] and with the research conducted by Ozaki et al. (2008), that physicians, differently than most of the literature advocates, are workers who are more humane than normally believed. This research reinforces that physicians want to work in an egalitarian and good working environment, seeing medicine as a job as much as a profession.

Trust in the hospital leaders came in third place in terms of contribution to explain the PC Index, followed by training and development, and work infrastructure. The position occupied by the dimension trust is a surprising result when one takes into account the emphasis that this dimension has received in previous studies done in various sectors and in healthcare $[22,10]$.

One could speculate that physicians are not overly affected by their relationship with their leaders because hospitals are professional bureaucracies, as pointed out by Minstzberg (1983), and physicians hold the technical knowledge, and consequently, the power. The fact autonomy has not been included in the regression equation reinforces this understanding, and might be explained by the characteristics of the profession itself, defined by much freedom of action. Perhaps the presence of autonomy is not relevant, since it is inherent to the job [18], but it is possible that its absence awakens negative behaviors and attitudes on the part of these professionals.

Another interesting point is the observation that training and development and work infrastructure assumed relatively less importance than the other variables that entered into the regression equation. This may be explained by the fact that in this research the interviewed physicians work in private hospitals of excellence, offering their clinical staff a good work infrastructure and the opportunity of professional development. Likewise, perhaps nursing contingent was not included in the regression equation because this is not a problem in hospitals of excellence, which usually have enough nurse professionals to assist physicians.

\section{Conclusions}

The primary objective of this research is to broaden the understanding of how to manage the physicians in such a way as to generate positive behaviors and attitudes of these professionals in relation to the hospitals in which they work. To meet this objective, the dimensions of internal climate for physicians have been investigated, as well as the dimensions of positive consequences in terms of their behaviors and attitudes. Based on the literature, the analytical model proposed relates some dimensions of the internal climate to the physicians' positive attitudes and behaviors, measured by the $P C$ index.

The results have indicated that, for the physicians involved in this research, five dimensions of internal climate contribute to explaining their positive attitudes and behaviors: camaraderie, non-discrimination, trust, training and development and work infrastructure. These five dimensions explain $58.60 \%$ of the total variation of $P C$ index. Therefore hypothesis $\mathrm{H} 1$ has been partially confirmed, since nursing contingent and autonomy did not help to explain the positive attitudes and behaviors of the physicians investigated in this research. Fig.2 presents the final model.

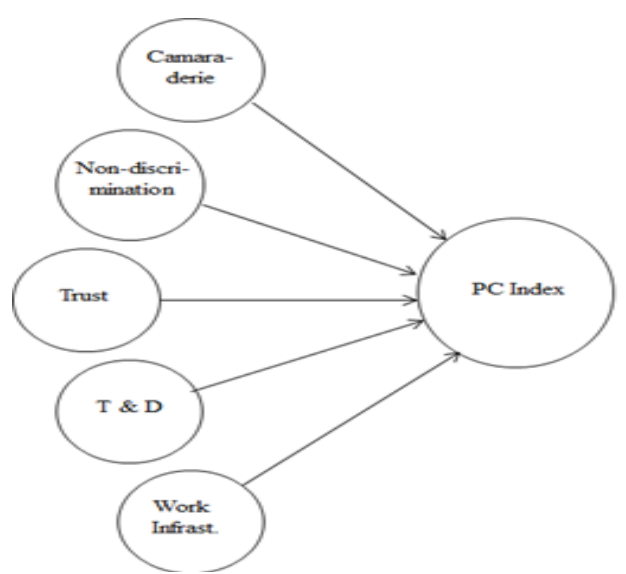

Fig. 2: Dimensions of internal climate that contribute to explaining the PC Index 
In order to stimulate positive behaviors and attitudes in physicians ( $P C$ index), hospital leaders should emulate a good work environment among the staff (camaraderie), and create an environment free of discrimination on the grounds of age, gender or ethnicity (nondiscrimination). Hospital leaders should also establish a trusting relationship with doctors (trust) through clear and effective communication, based on respect. It's also important to offer development opportunity for these professionals (training and development) and a good work infrastructure.

It's surprising that non-discrimination is one of the dimensions that contribute most to the physicians' $P C$ Index, since this factor has not emerged from the literature review. So far, absence of discrimination has been investigated as one of the attributes that comprise the dimension justice within the organizational environment; in this study, however, nondiscrimination emerged as an independent dimension that has a large influence on the physicians' positive attitudes and behaviors. Besides, the great importance of camaraderie to explain the PC Index is also interesting, once these results reveal that physicians are not that

\section{References}

1. Leebov W (2008) Physician Entrepreneurs: The Quality Patient Experience: Improve Outcomes, Boost Quality Scores, and Increase Revenue. HCPro, Inc, Marblehead.

2. Mintzberg H (1983) Structure in Fives: Designing Effective Organizations. Prentice Hall, Upper Saddle River.

3. Hoff TJ (2001) The physician as worker: what it means and why now? Health Care Management Review, 26(4): 53-70.

4. Ozaki M, Bito S, Matsumura S (2008) Developing a Japanese hospital physician satisfaction scale, International Journal of Health Care Quality Assurance, 21(5): 517-28.

5. Schneider B, The service organization: climate is crucial. In: Bateson JEG, org. (1995) Managing Services Marketing. 3rd ed. Dryden Press, Orlando.

6. Lau R (2000) Quality of work life and performance: an ad hoc investigation of two key elements in the service profit chain model. International Journal of Service Industry Management, 11(5):422-37.

7. Rego A, Souto S (2004) Comprometimento organizacional em organizações autentizóticas: um estudo luso-brasileiro, Revista de Administração de Empresas, 44(3):30-43. individualistic and that they value an egalitarian and good working environment. Like any other professional, physicians benefit from a good relationship with their peers.

This study contributes to broadening the understanding about the antecedents of positive attitudes and behaviors on the part of physicians of hospital institutions, since most of the previous studies have focused on studying nursing professionals. However, it must be pointed out that the results presented herein should not be generalized, since the physicians investigated in this research work at private hospitals in Brazil recognized for the excellence of their services and who offer good working conditions for their physicians. In addition, some limitations of a conceptual and methodological order must be considered, such as the subjectivity of the information furnished by the respondents and the interpretation of the data by the researcher, the absence of the researcher during the filling out of the questionnaires, the order in which the questions were presented (which could have introduced some bias in the responses) and, finally, the fact of the sample being comprised of respondents who made themselves available to participate in the research.

8. Peduzzi M (1998) Equipe multiprofissional de saúde: a interface entre trabalho e interação. Ph.D. thesis, State University of Campinas.

9. Mano-Negrin R (1998) Occupational determinants of work attitudes and organizational attachment. Health Manpower Management, 24(4):153-60.

10. Rad AM, Yarmohammadian MH (2006) A study of relationship between managers' leadership style and employees' job satisfaction, Leadership in Health Services, 19(2):11-28.

11. Williams ES, Rondeau KV, Xiao Q, Francescutti LH (2007) Heavy physician workloads: impact on physician attitudes and outcomes. Health Services Management Research, 20(4):261-9.

12. Henry K, Julius K (2011) Organizational internal environment, role clarity and citizenship behavior at casualty emergency centers, Journal of Behavioral Studies in Business, 4:1-14.

13. Miryala RK, Thangella S (2012) Job satisfaction amongst doctors. IUP Journal of Management Research, 11(3): 68-87.

14. Lyman A (2003) Building trust in the workplace: why trust brings out the best in your employees. Strategic Human Resources Review, 3(1):24-27.

15. Lambrou P, Kontodimopoulos N, Niakas D (2010) Motivation and job satisfaction among medical 


\section{Available online at www.managementjournal.info}

and nursing staff in a Cyprus public general hospital. Human Resources for Health, 8:1-9.

16. Kartal SB, Ates M, Ozcan I, Soyuk, S (2011) Research on determining employee satisfaction of physicians working at primary health services. Journal of Alanya Faculty of Business / Alanya Isletme Fakültesi Dergisi, 3(2):1-17.

17. Kairys J, Zebiene E, Sapoka V, Zokas I (2008) Satisfaction with organizational aspects of health care provision among Lithuanian physicians, Central European Journal of Public Health, 16(1):29-33.

18. Iliopoulos E, Priporas CV (2011) The effect of internal marketing on job satisfaction in health services: A pilot study in public hospitals in Northern Greece, BMC Health Services Research, 11(1): 261-9

19. Matzler K, Renzl B (2007) Personality traits, employee satisfaction and affective commitment. Total Quality Management \& Business Excellence, 18(5):589-98.

20. Alizadeh Z, Darvishi S, Nazari K, Emami M (2012) Antecedents and consequences of organizational citizenship, Interdisciplinary Journal of Contemporary Research in Business, 3(9):494-505.

21. Tamayo A (1998) Valores organizacionais: sua relação com satisfação no trabalho, cidadania organizacional e comprometimento afetivo. Revista de Administração, 33(3): 56-63.

22. Ogunnaike O, Oluseye (2011) Assessing the effect of organizational commitment on service quality; a study of customer-contact employee, Global Journal of Management And Business Research, 11(2):33-40.

23. Williams ES, Skinner AC (2003) Outcomes of physician job satisfaction: a narrative review, implications, and directions for future research. Health Care Manage Review, 28(2):119-40.

24. Chen Z, Tsui A, Farh J (2002) Loyalty to supervisor vs. organizational commitment: relationships to employee performance in China, Journal of Occupational and Organizational Psychology, 75(3):339-56.

25. Wasti SA (2003) Organizational commitment, turnover intentions and the influence of cultural values. Journal of Occupational and Organizational Psychology, 76(3):303-321.

26. Allen NJ, Meyer, JP (1990) The measurement and antecedents of affective, continuance and normative commitment to the organization, Journal of Occupational Psychology, 63(1):1-18.

27. Allen NJ, Meyer JP (1996) Affective, continuance and normative commitment to the organization: An examination of construct validity. Journal of Vocational Behavior, 49(3):252-76.

28. Huang MC, Liu TC (2010) The impact of external environment and self-serving motivation on physician's organizational citizenship behaviors, Journal of Behavioral Studies in Business, 2:1-10.

29. Bellou V, Thanopoulos J (2006) Enhancing service quality in a hospital setting, Review of Business, 27(1): 26-32. 